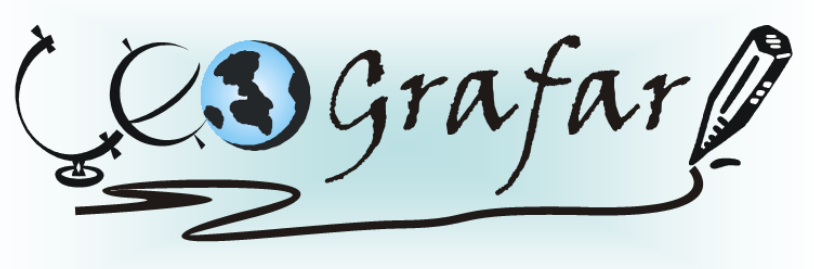

Revista Eletrônica do Programa de Pós-Graduação em Geografia - UFPR

\title{
DESASTRES NATURAIS OU NEGLIGÊNCIA HUMANA?
}

\author{
ROSA MOURA ${ }^{2}$ \\ LUÍS ANTONIO DE ANDRADE E SILVA
}

\begin{abstract}
RESUMO: A expressão "desastre natural" é questionada no presente trabalho, que considera que fenômenos naturais provocam desastres em função das formas de produção, ocupação e uso do espaço. A partir de uma perspectiva geográfica, esse entendimento é discutido associando-o a conceitos correlatos, como hazard, perigo, risco, desastre ou catástrofe, vulnerabilidade socioambiental, assim como à importância das condições técnicas e culturais no controle de um risco. A análise distingue situações de risco decorrentes de fenômenos com forte intensidade - agudos, com efeitos vorazes e catastróficos, mas duração passageira - dos danos cotidianos resultantes de fenômenos naturais, enquanto ações crônicas. Em qualquer dos casos, as populações mais afetadas são as mais pobres. Nesse sentido, o trabalho coloca ênfase nos efeitos perversos da combinação pobreza/urbanização/meio ambiente, afetando a qualidade da vida urbana e expondo a população a situações de risco devido a processos naturais e humanos, e chama a atenção às conseqüências cotidianas da opção por um modelo inadequado e insustentável de apropriação e uso do espaço e dos recursos naturais. Tal opção vem acelerando o efeito estufa e o aquecimento global, cujas consequiências climáticas, mesmo que afetem toda a humanidade, virão a incidir mais tragicamente sobre grupos vulneráveis. O trabalho sugere análises, pesquisas e procedimentos técnicos voltados à eliminação dos efeitos de desastres, e recomenda sua adoção no planejamento e gestão urbana, sublinhando a importância da participação da comunidade e do fortalecimento do papel do Estado na condução do processo.
\end{abstract}

PALAVRAS-CHAVE: Fenômenos naturais, desastres, riscos, vulnerabilidade socioambiental.

\begin{abstract}
The expression "natural disaster" is questioned in the present work, as it considers that natural phenomena can provoke disasters just in function of the forms of production, occupation and use of the space. In a geographic perspective, the expression is argued associating it to correlated concepts, as hazard, danger, risk, disaster or catastrophe, social-environmental vulnerability, as well as to the importance of cultural and techniques conditions on risk management. The analysis distinguish situations that results from phenomena with strong intensity - acute, with voracious and catastrophic effects, but with a short action - to those that are resultant of daily damages of natural phenomena, as chronic actions. In both cases, the most affected populations are the poorest. This work emphasizes the combination of poverty/urbanization/environment affecting the quality of the urban life and submitting this segment to situations of risk due to natural or human processes. It warns to the daily consequences of the option for an inadequate and unsustainable model of appropriation and use of the space and natural resources. Such option is speeding up the greenhouse effect and the global warming, whose climatic consequences, although affect all humanity, will occur more tragically on vulnerable groups. This work suggests analyses, researches and technical procedures directed to eliminate the effect of disasters, and their adoption in the urban planning and management, emphasizing the importance of community participation and the strengthen of the State position in the lead of the process.
\end{abstract}

KEY WORDS: Natural phenomena, disasters, risk, social-environmental vulnerability.

\footnotetext{
${ }^{1}$ Trabalho apresentado na Mesa Redonda "Papel del ordenamiento territorial y urbano en la gestión del riesgo por desastres naturales", na Convención de Ordenamiento Territorial y Urbanismo, promovida pelo Instituto de Planificación Física, La Habana, outubro/novembro de 2007.

${ }^{2}$ rosamoura@ipardes.pr.gov.br
} 


\section{INTRODUÇÃO}

O presente trabalho visa subsidiar a discussão acerca da importância dos instrumentos de planejamento e gestão do território na prevenção de riscos por fenômenos naturais, em particular em espaços com vulnerabilidade no hábitat. Como contribuição ao debate, o trabalho questiona o emprego da expressão "desastre natural" e acentua a importância de se considerar a vulnerabilidade socioambiental na gestão territorial de riscos.

A abordagem considera duas situações distintas: aquelas situações de risco decorrentes de fenômenos com forte intensidade, agudos, com efeitos vorazes e catastróficos, como terremotos, tsunamis, erupções vulcânicas, furacões, porém de duração passageira; e os danos cotidianos de fenômenos naturais, enquanto ações crônicas, com incidência mais perversa em hábitat e populações vulneráveis, como tormentas sucedidas de inundações urbanas ou deslizamentos - fatos mais comuns no Brasil. Qualquer que seja a condição, o que é verdade é que as populações pobres são as mais afetadas.

\section{ABORDAGEM CONCEITUAL}

A noção básica que orientou a análise foi a de que os "desastres" não são naturais, mas decorrentes da ação humana. Eventos naturais somente se convertem em desastres quando seres humanos vivem nas áreas onde ocorrem e agravam as causas de seus processos. Assim, a presença de fatores ambientais faz parte da vida urbana, porém os danos ambientais resultam de causas físicas (geológicas, climáticas) e da ação humana. Os impactos dos fenômenos naturais na sociedade tornam-se problemáticos pelo modo de ocupação do solo, pela qualidade construtiva e pela presença ou ausência de infra-estrutura adequada.

Outra noção demarcada no trabalho foi a de "vulnerabilidade", que envolve riscos com implicações sociais, econômicas, tecnológicas, culturais, ambientais e políticas, diretamente vinculados à manifestação mais nítida de carência de poder de grupos específicos, porém numerosos na humanidade (DESCHAMPS, 2004).

Considerando as relações entre a produção do espaço, a forma como as sociedades ocupam e usam o território, e a sujeição a riscos de fenômenos naturais a partir de uma perspectiva geográfica, algumas outras noções foram destacadas da literatura especializada. 
Marandola Jr. e Hogam (2004) discutem o recorrente conceito de hazard como eventos que rompem um ciclo ou um ritmo de ocorrência de fenômenos naturais, na interface sociedade-natureza. Os hazards estão relacionados às inundações, terremotos, erupções vulcânicas, vendavais, furacões, nevascas, secas, ciclones tropicais, erosão, avalanches, entre outros; porém só adquirem sentido de desastres quando ocorrem ou se relacionam às áreas ocupadas por humanos, gerando perdas, danos e colocando populações em perigo. O pressuposto é que, por definição, não existem hazards naturais, porém sempre relacionados a iniciativas e escolhas humanas, resultantes da interação dos humanos com sistemas naturais físicos e biológicos. Os autores citam ainda hazards associados à interação naturezasociedade-tecnologia, estes híbridos, compondo diferentes níveis de vulnerabilidade (ambiental, tecnológica, social etc.).

Hazard vem sendo traduzido como "risco", posto que considera os elementos antropogênicos e a "possibilidade de perigo". Essa tradução, entretanto, não distingue o fato de que o risco também representa um momento anterior ao hazard. Smith (1992) faz a distinção, apontando que o risco contém um fator de probabilidade, enquanto o hazard representa um evento danoso, que põe em perigo, realizado como um "desastre".

Aneas de Castro (2000) reitera essa noção, afirmando que o conceito de risco "incluye la probabilidad de ocurrencia de un acontecimiento natural o antrópico y la valoración por parte del hombre en cuanto a sus efectos nocivos". É a probabilidade de realização de um perigo, enquanto desastre é o resultado de um perigo derivado de um risco. Aclara os termos desastre ou catástrofe, que em sentido amplo, referem-se a um acontecimento súbito, inesperado ou extraordinário, que provoca prejuízos aos indivíduos. Sintetiza sua reflexão com base em Smith (1992, p.6): "é a realização do perigo".

Em geral, pode-se considerar que o conhecimento e um aporte tecnológico adequado podem livrar as populações de situações de risco ou perigo, evitando os desastres. GarcíaTornel (1984) observa que as condições técnicas e culturais de um determinado grupo humano frente a seu meio tornam o risco uma situação concreta, na medida de quanto este grupo é capaz de aproveitar as condições do meio para sua sobrevivência, ou incapaz de dominá-las, o que torna um evento mais ou menos perigoso. Ou seja, é o estado das sociedades humanas o que tornará um evento mais ou menos perigoso. "Dicho de otra manera: es el nivel cultural y técnico de los distintos grupos humanos el que determina, en un 
momento dado, cuales de los elementos que conforman el medio son 'recursos' y cuales son amenazas o 'resistencias' para el hombre."

Assim, populações desprovidas de meios de proteção ou sem recursos tecnológicos estariam mais vulneráveis aos efeitos de fenômenos naturais. $\mathrm{Na}$ contemporaneidade, o conhecimento científico permite e deveria ser endereçado continuamente para fazer o sistema humano menos vulnerável a esses fenômenos da natureza, descobrindo possibilidades de enfrentar os acontecimentos naturais que excedem a capacidade de absorção do sistema simples de uso do meio.

Para García-Tornel (1984), "no existe el riesgo sin tener presente su trascendencia para el hombre y las modificaciones que este puede introducir en aquel. Iniciativa y acción humanas son componentes esenciales de peligro: si no hay población las inundaciones no son riesgos, los terremotos del Terciario tampoco lo son." Assim, a noção de catástrofe apresenta maior relação com a amplitude de seus efeitos humanos que com seus próprios caracteres físicos. O fator social é de indubitável importância e busca as diversas possibilidades de adaptação e defesa contra os diferentes riscos, muito distintas segundo o grau de coesão social dos diversos grupos e a tecnologia de que dispõem.

Por isso, algumas populações ou segmentos delas se tornam, em distintos graus, vulneráveis aos riscos; situação que se relaciona com as condições sociodemográficas da população. Ribeiro (2005) mostra que, segundo a Comissão Econômica para a América Latina e o Caribe (CEPAL), a "qualidade de vulnerável" é a qualidade que aplica àquilo "que pode ser ferido ou receber lesão física ou moral”, e para que se produza um dano devem concorrer: um evento adverso em potencial, ou seja, um risco, que pode ser exógeno ou endógeno; uma incapacidade de resposta frente a tal contingência, devido à ausência de defesas idôneas ou à carência de fontes de apoio externas; e uma inabilidade de adaptação ao novo cenário gerado pela materialização do risco. Com o objetivo de identificar os territórios socialmente vulneráveis das metrópoles brasileiras, o autor assume vulnerabilidade, em sua acepção social, como "a situação de risco que veda ou bloqueia os segmentos mais fragilizados socialmente de adquirirem os recursos necessários à sua plena integração em sociedade".

Para Deschamps (2004), a noção de vulnerabilidade social estaria diretamente relacionada a grupos ou indivíduos que, por determinadas características ou contingências, particularmente decorrentes de sua relação com o poder, vivem menos propensos a dar 
resposta positiva ante algum evento adverso. Tomando por base autores entre os quais destaca Kaztmam (1999 e 2000), conclui que a noção de vulnerabilidade está vinculada à de pobreza e é componente de crescente importância quando se trata de desvantagens sociais e demográficas. Quanto maior a incidência de fatores que promovam desvantagem sóciodemográfica, em famílias ou indivíduos residentes em determinadas áreas, maior o grau de vulnerabilidade, pondo em evidencia a desigualdade socioespacial.

No âmbito da vulnerabilidade social, outra noção, mais restrita, é a de vulnerabilidade demográfica, que corresponde a "un conjunto de características demográficas de las unidades domésticas que, en una sociedad moderna, limitan la acumulación de recursos" (VIGNOLI, 2000, p.7). A vulnerabilidade demográfica está vinculada aos fatores geradores e/o expressões da desvantagem social, ou seja, aquelas condições sociais que afetam negativamente comunidades, lares e pessoas, em termos de menores acesos (conhecimento e/ou disponibilidade), e capacidades de gestão dos recursos e das oportunidades de desenvolvimento. Para Vignoli (2000, p.13), esta "situación de desmedro se origina en los factores que constituyen el ordenamiento social imperante y no en las habilidades inherentes o las decisiones libres de los individuos." O autor (2000, p.7) afirma que a "vulnerabilidad demográfica es un eslabón de la compleja cadena de limitaciones y precariedades que aqueja a los grupos postergados de la región; reducirla contribuiría a disminuir sus desventajas sociales y promovería mayores opciones de vida y de movilidad social".

Em dado ambiente de segregação socioespacial, esses segmentos se põem mais vulneráveis aos efeitos desastrosos dos fenômenos naturais, o que coloca em ênfase a noção de "vulnerabilidade socioambiental".

García-Tornel (1984) pontua outros fatores de ordem social e institucional que se combinam e levam a que determinados riscos produzam efeitos nocivos sobre as populações: além do modelo de desenvolvimento econômico, sob adoção de formas segregativas de apropriação e uso do solo, a inexistência ou inoperância de organismos encarregados de prevenir ou paliar tais acontecimentos, a completa falta de possibilidades de evacuação ante a informação de um fenômeno iminente e de medidas de alerta, além do que chama "sentimento de falsa segurança". Nesse sentido, a vulnerabilidade vem pondo em evidência uma insistência, por opção ou falta dela, das populações em ocupar áreas perigosas; as formas de adaptação (precária) ao risco a partir da convivência com o perigo; a completa falta de possibilidades de evacuação ante a informação de um fenômeno iminente e de medidas de 
alerta. Ironiza o autor que, ainda que este seja o caminho que pode conduzir ao melhor nível de adaptação, de momento há que se contentar em "saber dónde vivir para evitar el peligro y cómo vivir con el peligro sí es inevitable".

Tal compreensão coloca em pauta uma concepção subjetiva do risco. Considerando as estratégias de populações determinadas no enfrentamento de situações de risco, Cardoso (2006) discute a noção de risco, com base em abordagens sociológicas que postulam que essa noção é fruto de uma construção social, como produto de diferentes percepções que integram visões de mundo, culturas e estruturas de sociabilidade específicas a determinados grupos sociais. Assim, há uma "relativização das percepções do risco, na medida em que as vivências urbanas são diferenciadas segundo a classe sociais e as opções ideológicas dos diferentes grupos". (CARDOSO, 2006, p.45) Alerta o autor sobre o quanto o saber científico e técnico tem avançado em análises, cálculos, mapeamentos, e desconsiderado as necessidades e experiências das populações, imputando a determinados territórios e suas populações o "estigma do risco" - expresso na ameaça da remoção, do deslocamento compulsório entre outras medidas - como se suas estratégias de ação fossem o resultado da "ignorância técnica".

Como se as escolhas e as práticas não fizessem parte de um horizonte de vida e de uma trajetória social que fazem sentido, dentro do quadro de exclusão, da precariedade e dos limites que marcam a vida em assentamentos populares urbanos. (CARDOSO, 2006, P.45)

\section{PREVENÇÃO, PLANEJAMENTO E RECUPERAÇÃO}

Tomando em conta a urbanização crescente, a ação dos fenômenos naturais se agrava na combinação urbanização/pobreza/meio ambiente. A associação entre a falta de regulação do uso e ocupação do solo, iniqüidade socioespacial e rápido crescimento urbano, em contexto de pobreza, é a causa de grandes problemas e provoca os mais sérios elementos de risco. Abordagens integradas entre variáveis humanas e físicas se fazem necessárias para oferecer soluções efetivas aos problemas interrelacionados de pobreza e ambiente. Os sintomas da pobreza marcam fortemente a vida urbana e é impossível exterminá-los se não são priorizados nas estratégias de gestão e inversões nas grandes cidades dos países subdesenvolvidos.

Entre os agravos considerados crônicos, problemas ambientais são gerados pelas próprias cidades, como a poluição do ar e da água, associada ao uso de veículos e inadequada 
infra-estrutura viária, industrialização desregulada, suburbanização e favelização com ausência de saneamento. Esses agravos se agudizam em situações de governança de baixa qualidade, antidemocráticas e pouco éticas, conduzidas por interesses corporativos, resultando na elevação dos indicadores de vulnerabilidade social: carência e deficiência no acesso aos serviços essenciais e elevação da mortalidade e morbidade por causas evitáveis, entre outros danos sociais, ambientais e econômicos, como as próprias condições de fluxos e acesso a uma cidade com vida saudável.

Comuns aos acidentes naturais são os efeitos que implicam elevado número de vítimas e impactos físicos sobre moradias, equipamentos sociais e infra-estruturas. Em países pobres, surpreende a limitada capacidade de recursos para socorro, alojamento de emergência, oferta de alimentos, água e eletricidade, assim como condições sanitárias e comunicações. Incrementam, dessa forma, os déficits de oferta, comuns a esses países. Além da desestruturação física, humana e material, engendram uma sucessão de problemas sociais que intensificam os efeitos das calamidades. É o caso do desemprego e da redução ainda maior dos salários em grupos de baixo rendimento, além de transtornos secundários na economia (GASTAL, 1987).

Ante a inevitabilidade dos fenômenos que impulsionam tais desastres, devem-se escolher medidas permanentes de prevenção e planejamento para evitar seus impactos, e de preparo para atenção às vítimas, caso ocorram. Evidentemente, muitas medidas implicam um volume elevado de recursos, porém este será insignificante se consideradas as conseqüentes perdas que acompanham as tragédias.

Medidas preventivas, com o fim de evitar que fenômenos naturais resultem em desastres, relacionam-se a estudos e pesquisas científicas para determinar a natureza, intensidade, periodicidade, duração e distribuição geográfica dos fenômenos. Requerem suporte em redes de monitoramento para acompanhar o desenvolvimento e a evolução dos eventos, e em sistemas de advertência preventiva nas áreas sujeitas a eles. Complementam-se com regulamentos e normas técnicas dispostos em instrumentos legais e jurídicos, particularmente: leis de zoneamento que considerem a posição geográfica e a vulnerabilidade do solo; códigos de obras que assegurem condições nas edificações para suportar os efeitos dos fenômenos naturais; assim como são imprescindíveis políticas de moradia e programas educativos sistemáticos, que instruam acerca dos efeitos dos desastres e as atitudes básicas de prevenção e socorro. 
Em termos de planejamento, é necessário incorporar metodologias de análise de vulnerabilidade a desastres em projetos de grande porte, principalmente assentamentos humanos. O planejamento de longo prazo deve considerar programas de capacitação para socorro, medidas de contingência para o caso de ocorrências, e suporte imediato à reabilitação e reconstrução, pós eventos calamitosos. Ou seja, planos de emergência, criação de agências de socorro, treinamento de pessoas e estabelecimento de fundos especiais para emergências (GASTAL, 1987).

Trabalhos de reconstrução não podem concentrar-se em um único setor, porém integrar todos os setores que impliquem restaurar as condições de habitabilidade e funcionamento da cidade. Outro tema de grande importância em trabalhos de reconstrução e reabilitação de áreas afetadas por desastres naturais remete à coordenação dos trabalhos de responsabilidade das autoridades públicas envolvidas, ou que impõem manutenção e reforço das equipes técnicas das entidades governamentais encarregadas dessa tarefa (SANTOS, 1987).

Comprova-se que, em países pobres, a maior parte dos afetados são populações carentes. Soluções provisórias aos agravos, quando implementadas, muitas vezes se convertem permanentes, posto que a correlação de forças entre esses segmentos sociais e os centros de decisões, de modo geral, impele os primeiros a que acumulem perdas. Assim, a condução das atividades pelo Estado e o controle social são fundamentais para garantir a atenção aos mais necessitados.

García-Tornel (1984) assevera que,

de forma menos tangible, pero no menos importante, los diversos estudios han demostrado sobradamente que la imagen que tienen los habitantes de lugares peligrosos sobre sus riesgos y el abanico de posibilidades para evitarlos o paliarlos suele ser bastante diferente de la que tienen técnicos y políticos, de manera que si hay que realizar una política eficaz en relación con los riesgos naturales (o más ampliamente, de gestión de recursos) la participación popular es imprescindible.

Como cada coletividade ou individuo escolhe a forma de adaptar-se ao risco, mediante uma escala de valores que se referem à sua compreensão sobre a organização do território, à possibilidade técnica de sua decisão, caráter econômico e transcendência social, "la investigación de los riesgos naturales adquiere una dimensión política, en cuanto cualquier 
tipo de decisión puede generar tensiones y reacciones muy distintas entre el grupo afectado, singularmente si existe una clara conciencia colectiva sobre el riesgo." (GARCIA-TORNEL, 1984).

Todas essas considerações remetem ao que conclui Mendonça (2004) quanto a que muitas são as soluções para problemas socioambientais urbanos, porém não se logrará êxito sem a implementação de uma gestão urbana com participação social, sem o fortalecimento do papel do Estado (setor público) na condução do processo, e sem haver cidadania e democracia.

\section{SITUAÇÕES AGUDAS E CRÔNICAS}

Muitos casos ilustram as idéias expostas e, entre os mais recentes, não se pode omitir as catastróficas conseqüências do tsunami na Indonésia, em 2004; do furacão Katrina, em Nova Orleans, Estados Unidos, em 2005, do terremoto em Pisco, Peru, e dos inúmeros furacões e ciclones que vêm assolando regiões sem ocorrências comuns. Em todos, pesou a forma de ocupação do espaço, a opção construtiva e a ausência de preocupação pública em disponibilizar recursos tecnológicos como meio preventivo às tragédias - algumas anunciadas, como o incidente do Katrina, onde emerge ainda o componente político e, em grande medida, o étnico.

Douglas e Gilbert (2004) enfatizam que a expansão urbana mundial ocorre em cidades localizadas em áreas potencialmente perigosas em relação a fenômenos naturais: terremotos (Los Angeles, Tókio, Beijing, Manila, Cidade do México), inundações (Amsterdã, Buenos Aires, Dhaka, Calcutá, Lagos), ciclones tropicais (Dhaka, Manila, ilhas Caribenhas). A esses se juntam desastres tornados crônicos, como as inundações e deslizamentos comuns nas metrópoles brasileiras. Cada cidade adota medidas preventivas próprias que podem resguardar de riscos a população e conquistar melhor ou pior resultado, em função de posturas políticas e institucionais que operam na definição de prioridades e no aporte de recursos financeiros e tecnológicos destinados à implementação das medidas.

A partir de algumas comparações quanto às soluções entre países com elevada pobreza, esses autores colocam em evidência que a forma de enfrentamento dos fenômenos, com base em sistemáticas de planejamento e gestão, expõe em maior ou menor escala as populações 
pobres. Comparam o desempenho entre Manila e Cidade do México, ambas localizadas no círculo de fogo do Pacífico, sujeitas a terremotos, vulcões, ciclones, entre outros, mostrando que $35 \%$ das moradias em Manila e 60\% em Cidade do México ocorrem em assentamentos informais. Na primeira, um processo de planejamento e gestão participativa vem levando a resultados menos impactantes, enquanto na segunda cidade, os agravos se mostram maiores, dada a consentida localização em áreas vulneráveis a riscos. Problemas de circulação de veículos e congestionamento de trânsito, embora recorrentes, se mostram menos graves na Cidade do México, devido à existência do transporte de massa subterrâneo sobre trilhos, ante a total dependência do automóvel em Manila, que apresenta crescente índice de motorização e poluição atmosférica, principalmente por veículos sem equipamentos de controle de emissão de gases. Neste caso, o problema também é agudizado na Cidade do México, pela sua localização em elevada altitude, o que baixa o potencial combustível. Essa cidade sofre ainda por sua proximidade à barreira de montanhas, a qual amplia os efeitos de inversão térmica por conter a dispersão, e por problemas de subsidência agravada pela extração de água subterrânea.

Trazendo para a comparação a cidade de São Paulo, com seu crônico problema de inundações, também se percebe que, pelo planejamento e gestão adotados, apresenta resultados ainda mais problemáticos que a Cidade do México. Seu sitio topográfico condicionou a estrutura de circulação urbana, que aproveitou a rede hidrográfica para alocar as principais vias, como "marginais" aos cursos de água, adensando ocupação e usos nos mesmos corredores (MEYER et al., 2004). Essa é uma das dificuldades para o enfrentamento da questão, como destaca Custódio (2002), que aponta como crítica a própria localização da área metropolitana, sobre um planalto, no centro do qual está a bacia sedimentar de São Paulo, formada por densa rede hidrográfica e contornada por elevações; portanto, confinada, com grande facilidade de retenção de elevada quantidade de água, o que provoca na região a propensão à acumulação de água, e em consequiência, a inundações. A despeito das obras de retificação dos canais dos rios e drenagem, a ocupação vem impermeabilizando o solo e criando uma densa área de elevadas temperaturas, condicionando o aumento da pluviosidade e a retenção das águas despejadas.

O Conselho Estadual de Recursos Hídricos classifica as inundações na Região Metropolitana de São Paulo em dois tipos: as que ocorrem ao largo dos rios Tietê, Pinheiros e Tamanduateí, que afetam principalmente a circulação de veículos, e aquelas que ocorrem ao 
largo dos afluentes dispersos pela área urbana, onde vivem grandes contingentes de população (LUME, 2002). Ano a ano novos pontos de inundações surgem na região, ampliando deseconomias, pondo a cidade em desvantagem comparativamente a outras metrópoles. Tornam comuns matérias na imprensa com títulos semelhantes: "Índice de congestionamento é recorde em São Paulo", com extensão de 177 km em 10 de fevereiro de 2006 (FOLHA, 2006), ou "Tempestade de uma hora pára São Paulo, arrasta automóveis e isola moradias; as marginais se inundam e a cidade registra $183 \mathrm{~km}$ de congestionamento" (FOLHA, 2007).

Para os especialistas em hidrometeorologia, o dano pode ser sensivelmente diminuído com o desenvolvimento de tecnologias que aperfeiçoem os sistemas de previsão e alerta de inundações. Entretanto, a solução definitiva depende de uma reestruturação da organização urbana, já que o problema é a ocupação inadequada do espaço. Sistemas de previsão e alerta constituem o mais imediato enquanto solução, contribuindo para evacuar a população, reduzindo danos ou auxiliando na convivência com as águas. Soluções definitivas exigem ações estruturais, como ampliar canais de rios, desocupar as margens, instituir leis que disciplinem a impermeabilização do solo para aumentar taxas de infiltração, e implementar programas de educação ambiental relativos à questão dos resíduos urbanos (CASTRO, 2007).

Custódio (2002) afirma que as atuais medidas de combate a inundações utilizadas pelos poderes públicos se mostram ineficientes, posto que as obras construídas assumem efeitos provisórios e, não raro, acabam por causar danos ao problema inicial. "A situação tem se tornado um círculo vicioso", observa. Ainda que a autora ressalte a importância das obras, enquanto os poderes públicos não estabelecerem contato com a população, o problema persistirá se agravando. Existe um distanciamento entre Estado e comunidades, exatamente quando é imprescindível o diálogo com a população, para que se conheça sua percepção, concepção e representação do problema, e assim obter maior eficiência das políticas públicas urbanas.

Buscando romper essa barreira, e com vistas à implementação de uma política pública de gerenciamento de riscos relativos a inundações e deslizamentos, o Instituto de Pesquisas Tecnológicas juntamente com outras entidades de pesquisa vêm desenvolvendo estudos e mapeamentos de áreas de risco sujeitas a escorregamentos e solapamento de margens em assentamentos precários e loteamentos irregulares do município de São Paulo. As pesquisas geológico-geotécnicas avançam na análise da probabilidade de ocorrência dos processos relacionados à dinâmica externa, identificação dos setores de risco, análise de possíveis 
conseqüências dos processos e a indicação de medidas de intervenção adequadas para os diferentes casos. Somam-se aos resultados desses estudos ações de treinamento dado a prefeituras paulistas, sob coordenação da Defesa Civil Estadual, fundamentalmente prevendo o monitoramento de áreas consideradas críticas por meio de dados pluviométricos e meteorológicos (SOARES, 2007).

Comparativamente à Cidade do México, ambas consideradas megacidades pelo tamanho de suas populações, faltaria em São Paulo uma ampliação no sistema de transportes urbanos de massa sobre trilhos, e sua extensão às áreas pobres da cidade, assim como uma tarifação que viabilizasse seu uso por essa população (a título de exemplo, a tarifa do metrô na Cidade do México, em outubro de 2007, correspondia exatamente a $20 \%$ da mesma tarifa na cidade de São Paulo). E, evidentemente, um novo planejamento de vias de elevada circulação, em áreas que não as marginais.

\section{CONCLUSÕES}

Forças naturais raramente resultam em desastres humanos, salvo se as pessoas oferecem condições que tornem possíveis os desastres. Desastres se intensificam em cidades construídas em locais ambientalmente instáveis, sem provisão de infra-estrutura adequada e com construções estruturalmente frágeis, atingindo diretamente populações vulneráveis, condicionadas a uma situação de pobreza. Pobreza que deve ser entendida tanto em termos da presença de moradores com baixo rendimento, que sob ação do mercado de terras só encontram opção de morar em áreas impróprias e mal servidas, como em termos da inadequação ou desvio de recursos públicos na provisão de serviços essenciais e infraestrutura, particularmente a esses segmentos da população. Tais condições afetam a qualidade da vida urbana, expondo a população a situações de risco decorrentes de processos naturais ou humanos, contribuindo para acelerar a degradação ambiental e elevar a vulnerabilidade social.

Não obstante, a condição mais perversa de degradação ambiental advém do modelo de desenvolvimento econômico e da opção energética, do consumo desenfreado das classes abastadas e do crescimento geométrico do transporte individual, influenciando aceleradamente no efeito estufa e aquecimento global, cujas conseqüências climáticas, mesmo que afetem toda a humanidade, inevitavelmente vão incidir mais tragicamente sobre as populações vulneráveis, os mais pobres. 
Há que se chamar atenção ainda ao fato de que tão graves como as catástrofes repentinas são as conseqüências cotidianas da combinação urbanização e pobreza, sob esse modelo inadequado e insustentável de apropriação e uso do espaço e dos recursos naturais. Males que resultam da falta de saneamento e abastecimento de água potável, da poluição do ar e da água, da alta densidade da ocupação urbana sem controle, e da baixa qualidade das moradias e do hábitat matam mais que muitas catástrofes.

Para enfrentar tais problemas, devem ser intensificadas análises que articulem os aspectos físicos e humanos na avaliação de riscos de fenômenos naturais, na identificação de populações vulneráveis e no desenvolvimento de procedimentos que eliminem os efeitos dos desastres. Equipes multidisciplinares são necessárias na pesquisa, planejamento e gestão urbana. Devem compreender e considerar os elementos da vida cotidiana, como a dinâmica de apropriação do solo, principalmente de populações com baixa renda, a lógica que implica na segregação socioespacial, e o estado da provisão pública de serviços e infra-estrutura. Mais importante, devem assegurar a participação da comunidade, posto que ela contém informações fundamentais à tomada de decisões e à adoção de medidas de socorro, e buscar compreender os fundamentos da construção social da percepção do risco, os motivos reais que levam muitas vezes à resistência, como a inexistência de alternativas que efetivamente signifiquem melhora que o convívio com a ameaça, suportada graças às redes familiares e de vizinhança. Devem ainda garantir a presença reforçada do Estado (setor público) na condução do processo, e instaurar um efetivo controle social no planejamento e gestão.

Porém, mais que pesquisas acadêmicas ou práticas gerenciais, há que ser repensado o modelo de desenvolvimento, colocando como prioridade o enfrentamento e a busca definitiva de solução à exclusão social e à miséria urbana.

\section{REFERÊNCIAS}

ANEAS DE CASTRO, S.D. Riesgos y peligros: una visión desde la Geografía. Scripta Nova. Revista Electrónica de Geografía y Ciencias Sociales. Barcelona, n.60, 15 mar. 2000. Disponível em http://www.ub.es/geocrit/sn-60.htm Acesso em abril de 2007.

CARDOSO, A.L. Risco urbano e moradia: a construção social do risco em uma favela do Rio de Janeiro.Cadernos IPPUR, ano XX, n.1, jan./jul. 2006, p.27-48.

CASTRO, F. Tempestades sem controle. Agência FAPESP. Disponível em http://www.aomestre.com.br/mab/102 tempestades.htm (Acesso em maio de 2007). 
CUSTÓDIO, V. A persistência das inundações na Grande São Paulo. Tesis (Doctorado). São Paulo, 2002. Apresentada a Faculdade de Filosofia, Letras e Ciências Humanas (FFLCH), Universidade de São Paulo.

DESCHAMPS, M.V. Vulnerabilidade socioambiental na região metropolitana de Curitiba/PR. Curitiba, 2004. Tese (Doutorado em Meio Ambiente e Desenvolvimento) Universidade Federal do Paraná.

DOUGLAS, I.; GILBERT, A.G. Urbanization, development and the environment in a unequal world. In: MATHEWS, J.A.; HERBERT, D. Unifying geography. Common heritage, shared future. Oxfordshire, Routledge, 2004.

FOLHA DE SÃO PAULO. Chuva causa trânsito recorde em SP. São Paulo, 17/03/2007, p.1; p.C1., p.C2.

FOLHA on line. Índice de congestionamento bate recorde em São Paulo. Disponível em http://www1.folha.uol.com.br/folha/cotidiano/ult95u118191.shtml - 10/02/2006 - 19h13 (Acesso em maio de 2007).

GARCÍA-TORNEL, F.C. La geografía de los riesgos. Cuadernos Críticos de Geografía Humana. Universidad de Barcelona, Año IX. Número: 54, Noviembre de 1984. Disponível em http://www.ub.es/geocrit/geo54.htm Acesso en março, 2007.

GASTAL, A. Efeitos sociais e econômicos dos recentes grandes desastres naturais na América Latina e a necessidade de preveni-los. PNUD/MHU (Ministério de Habitação, Urbanismo e Meio Ambiente). Seminário Internacional "Estratégias e Ações Frente a Desastres Naturais”. Anais. Salvador, 1987, p.11-16.

KAZTMAN, R. (coord.). Activos y estructura de oportunidades: estudios sobre las raíces de la vulnerabilidad social en el Uruguay. Oficina del Programa de las Naciones Unidas para el Desarrollo. CEPAL, UNDP, Montevideo. 1999.

KAZTMAN, R. Notas sobre la medición de la vulnerabilidad social. 5. ${ }^{\circ}$ Taller Regional. La medición de la pobreza: métodos y aplicaciones (continuación) (LC/R.2026), Santiago de Chile, Banco Interamericano de Desarrollo (BID)-Banco Mundial-Comisión Económica para América Latina y el Caribe (CEPAL) - Instituto Brasilero de Defensa del Consumidor (IDEC), Aguascalientes, 6 al 8 de junio, 2000.

LUME. Laboratório de Urbanismo da Metrópole. Drenagem urbana e os pontos de inundação no Município de São Paulo. Base de dados: SÃO PAULO (Cidade), Secretaria de Governo. São Paulo Protege. Operação contra as enchentes. São Paulo, PRODAM, 2002(Cd-Rom).

MARANDOLA JR, E.; HOGAN, D.J. Natural Hazards: o estudo geográfico dos riscos e perigos. Ambiente e Sociedade, São Paulo (Annablume/ANNPAS/UNICAMPNEPAM/CNPq), v. VII, n. 2, jul./dez. 2004, p. 95-109.

MENDONÇA, F. Riscos, vulnerabilidade e abordagem socioambiental urbana: uma reflexão a partir da RMC e de Curitiba. Desenvolvimento e Meio Ambiente, n.10, p.139-148, jul./dez. 2004. Editora UFPR.

MEYER, R.M.P.; GROSTEIN, M.D.; BIDERMAN, C. São Paulo Metrópole. São Paulo, EDUSP, Imprensa Oficial, 2004.

RIBEIRO, L.C. de. Q. Identificação de territórios vulneráveis. In. RIBEIRO, L.C.de Q. e SANTOS JUNIOR, O.A. As metrópoles e a questão social brasileira. Editora Revan/Observatório das Metrópoles, Rio de Janeiro, 2007. 
SANTOS, C.R. Abertura. PNUD/MHU (Ministério de Habitação, Urbanismo e Meio Ambiente). Seminário Internacional "Estratégias e Ações Frente a Desastres Naturais". Anais. Salvador, 1987, p.7-9.

SMITH, K. Environment hazards: assessing risk \& reducing disaster. London, Routledge, 1992, 324p.

SOARES, E. Los trabajos de gestión de riesgo en las áreas de deslizamiento en São Paulo. Apresentação de temas livres orais. Evento de Ordenamiento Territorial. Convención de Ordenamiento Territorial y Urbanismo. La Habana, nov. 2007.

VIGNOLI, J.R. Vulnerabilidad demográfica: una faceta de las desventajas sociales. Serie Población y Desarrollo, 5. Proyecto Regional de Población CELADE-FNUAP (Fondo de Población de las Naciones Unidas). Santiago de Chile, septiembre de 2000.

(Recebido em novembro/07. Aceito em outubro/08) 